\title{
Reinterventions after dynamic intraligamentary stabilization in primary anterior cruciate ligament repair
}

\author{
Janosch Häberli ${ }^{\mathrm{a}, *, 1}$, Laurenz Jaberg ${ }^{\mathrm{a}, 1}$, Kathrin Bieri ${ }^{\mathrm{b}}$, Stefan Eggli ${ }^{\mathrm{a}}$, Philipp Henle ${ }^{\mathrm{a}}$ \\ a Sonnenhof Orthopaedic Centre, Buchserstrasse 30, 3006 Bern, Switzerland \\ ${ }^{\mathrm{b}}$ Institute of Social and Preventive Medicine, University of Bern, Finkenhubelweg 11, 3012 Bern, Switzerland
}

Keywords:

ACL

Reintervention

Revision

Primary ACL repair

Dynamic intraligamentary stabilization

\begin{abstract}
A B S T R A C T
Background: The goal of this study was to perform an in-depth analysis of the frequency and cause of secondary interventions subsequent to primary anterior cruciate ligament (ACL) repair with dynamic intraligamentary stabilization (DIS).

Methods: Between July 2009 and June 2014, 455 patients underwent DIS treatment. The minimum follow-up was 21 months (mean 28 months, range 21-64 months).

Results: A total of 215 (48.2\%) reinterventions were performed in 190 (42.6\%) patients. Onehundred and seventy-six (39.4\%) were non-revision reinterventions, and 39 (8.7\%) were revision ACL reconstructions. Re-arthroscopies included 26 (5.8\%) scar tissue debridements with hardware removal due to range of motion deficits, 14 (3.1\%) partial meniscectomies, four $(0.9 \%)$ meniscal sutures, and four $(0.9 \%)$ arthroscopies due to crepitation or knee pain. Minor non-revision reinterventions performed under analgosedation consisted of 97 (21.7\%) hardware removals, 20 (4.5\%) hardware removals with manipulations under anesthesia, and four manipulations under anesthesia alone $(0.9 \%)$.

Conclusions: In our study, the revision rate was within the range of published results after ACL reconstructions. In over $90 \%$ of patients, the native ACL was preserved with no need for a secondary reconstruction. Most of the non-revision reinterventions were minor and included hardware removals and manipulations under anesthesia. The re-arthroscopy rate was lower than that after ACL reconstruction with fewer secondary meniscal sutures and partial meniscectomies. Early treatment of meniscal tears may be one crucial benefit of ACL repair with DIS.
\end{abstract}

\section{Introduction}

Dynamic intraligamentary stabilization (DIS) in primary anterior cruciate ligament (ACL) repair was clinically introduced in 2009. The technique combines transosseous suture repair of an acute ACL rupture with a dynamic internal brace using the Ligamys $^{\mathrm{TM}}$ implant and Steadman's healing response. Advantages of this technique include preservation of the native ligament with its proprioceptive nerve fibers and the lack of donor site morbidity because no graft harvesting is necessary. Recent studies have shown that this ACL preserving technique achieves good clinical mid-term results with high functional scores and patient satisfaction [1-5]. However, the revision rate in the current literature ranges from $2.8 \%$ to $20.0 \%$ depending on the follow-up period, cohort, and, most importantly, the definition of revision itself, which is not uniformly defined throughout the different studies [1-5]. The current literature provides no information regarding non-revision reinterventions after DIS.

\footnotetext{
* Corresponding author.

E-mail address: janoschhaeberli@sonnenhof.ch (J. Häberli).

1 These authors made equal contributions to this study.
} 
The goals of this study were, therefore, the following: (1) to determine the frequency of revision and non-revision reinterventions after DIS treatment; and (2) to analyze the different types of revision and non-revision reinterventions and the associated reasons. We hypothesized that: (1) the revision rate was in the range of published results after ACL reconstructions; and (2) non-revision reinterventions were performed more frequently.

\section{Methods}

\subsection{Study design and inclusion criteria}

We retrospectively reviewed all patients who underwent DIS repair for acute rupture of the anterior cruciate ligament at our clinic between July 2009 and June 2014. A total of 455 patients were included. A database search identified the patient population, and chart reviews were performed to determine patient age, gender, date of index and repeat procedures, interval between procedures, modes of failure, and indications for the reinterventions.

The indications for DIS treatment were as follows: acute ACL injury (time to surgery of 21 days or less), closed growth plates, and ineligibility for conservative treatment or unwillingness to accept it. Conservative treatment was recommended if all the following criteria were fulfilled: less than three-millimeter side-to-side difference to the uninjured contralateral side in the Lachman test with a Rolimeter; no pivoting sports; and no symptomatic meniscal lesions that required arthroscopic treatment.

The mean age of the patients at the index surgery was 32.9 years (standard deviation (SD), 11.8 years). In the reintervention group, the mean age of the patients was 31.2 years (SD, 11.5 years). Table 1 summarizes the baseline characteristics of the study population. The minimum length of follow-up was 21 months (mean 28 months, range 21-64 months). Nine patients were lost to follow-up, resulting in a follow-up rate of $98.0 \%$. Patients who did not present at the regular follow-up examinations were contacted by a study nurse or by residents to determine whether additional surgery had been performed outside our clinic.

Reinterventions were classified as either revisions, when a secondary ACL reconstruction was performed, or non-revision reinterventions, when no ACL reconstruction was required. The non-revision reinterventions were further classified into major reinterventions requiring arthroscopy or, on rare occasions, open surgery under regional or general anesthesia or minor reinterventions that were performed under analgosedation (hardware removal and/or manipulation under anesthesia (MUA)). Multiple reinterventions performed on the same patient were each considered separately. Two surgeons (PH and SE) were involved in decision making for reintervention. Indications for the respective reinterventions are found in Table 2.

\subsection{Operative technique and aftercare}

All primary procedures were performed by two experienced knee surgeons (SE, PH) who each perform approximately 100 ACL surgeries annually. All procedures were performed arthroscopically with the anteromedial portal technique. Tibial remnants of the torn ACL were attached to the femoral footprint with transosseous sutures, and microfracturing was performed at the femoral footprint. Anterior subluxation of the tibia was prevented with a polyethylene braid and a spring-screw implant (Ligamys ${ }^{\mathrm{TM}}$, Mathys Ltd., Bettlach, Switzerland) that was pre-loaded with 60-80 N of force.

Patients' knees were immobilized in an extension brace for four days, allowing early full weight-bearing. Beginning on day five, regular one-on-one physiotherapy sessions involved closed-chain quadriceps and range of motion (ROM) exercises for the first six weeks. Then, open chain exercises were allowed. Running was allowed after 10 weeks and return to pivoting sports after six months. Regular follow-up examinations were scheduled at three weeks, six weeks, three months, six months, one year, two years, and five years post-surgery.

\subsection{Data analysis}

All patients were informed that their treatment and follow-up data would be recorded in a scientific database for evidence generation and post-market surveillance of Ligamys ${ }^{\mathrm{TM}}$ and its outcomes, and they provided written informed consent. The study was approved by the Cantonal Ethics Committee of Berne, Switzerland (Ref.-Nr. KEK-BE: 048/09).

Table 1

Baseline characteristics of the study population.

\begin{tabular}{ll}
\hline $\mathrm{n}$ total & 455 \\
Male gender & $253(56 \%)$ \\
Female gender & $202(44 \%)$ \\
Age $($ years $)$ & $32.9 \pm 11.8$ \\
BMI $\left(\mathrm{kg} / \mathrm{m}^{2}\right)$ & $23.7 \pm 3.2$ \\
Previous contralateral injury & $46(10 \%)$ \\
Right side & $211(46 \%)$ \\
Left side & $244(54 \%)$ \\
Tegner preoperative & $5.1 \pm 1.5$ \\
\hline
\end{tabular}

BMI, body mass index. 
Table 2

Indications for reinterventions.

\begin{tabular}{|c|c|c|}
\hline Reinterventions & & Indications \\
\hline \multirow{4}{*}{ Revisions } & ACLR \pm meniscal suture or meniscectomy & Subjective and objective instability \pm new or persistent meniscal lesion \\
\hline & ACLR + ALL reconstruction & $\begin{array}{l}\text { Subjective and objective instability and }++ \text { to }+++ \text { pivot shift test or } \\
\text { contralateral positive pivot shift test }\end{array}$ \\
\hline & $\mathrm{ACLR}+\mathrm{HTO}$ & $\begin{array}{l}\text { Subjective and objective instability, grade III-IV (Outerbridge) } \\
\text { chondromalacia in medial compartment and varus axis }\end{array}$ \\
\hline & ACLR + cartilage repair & $\begin{array}{l}\text { Subjective and objective instability and grade III-IV (Outerbridge) } \\
\text { chondromalacia }\end{array}$ \\
\hline \multirow{8}{*}{ Major non-rev. reinterventions } & Scar tissue debridement with hardware removal & Combined ROM deficit \\
\hline & Meniscal suture or meniscectomy & New or persistent meniscal lesion \\
\hline & Arthroscopy due to crepitus or knee pain & Crepitus or unexplained knee pain \\
\hline & Lavage for septic arthritis & Septic arthritis \\
\hline & Cartilage repair procedure & Grade III-IV (Outerbridge) chondromalacia \\
\hline & ALL reconstruction & $\begin{array}{l}\text { Subjective and objective rotational instability with sufficient } \\
\text { translational stability }\end{array}$ \\
\hline & Wound debridement & Wound infection \\
\hline & Hematoma evacuation & Symptomatic large hematoma at tibial incision \\
\hline \multirow[t]{3}{*}{ Minor non-rev. reinterv. } & Hardware removal & Local discomfort or patient desire \\
\hline & Hardware removal and MUA & Local discomfort or patient desire and flexion deficit \\
\hline & MUA & Flexion deficit \\
\hline
\end{tabular}

ACLR, anterior cruciate ligament reconstruction; ALL, antero-lateral ligament; HTO, high tibial osteotomy; MUA, manipulation under anesthesia; ROM, range of motion.

\section{Results}

Of the 455 patients, a total of $215(48.2 \%)$ reinterventions were performed on 190 (42.6\%) patients (Table 3). Twenty-one patients underwent more than one reintervention; specifically, 19 patients had a second reintervention (nine ACL reconstructions, two ACL reconstructions combined with anterolateral ligament reconstruction, one ACL reconstruction with anterolateral ligament reconstruction and high tibial osteotomy, five arthroscopies, one meniscectomy, and one superficial hematoma evacuation), one patient had three reinterventions (hardware removal, ACL reconstruction, cartilage repair procedure), and one patient underwent five reinterventions (hardware removal, plica resection, arthroscopic lavage due to suspected infectious arthritis, and two MUAs).

Of the 215 reinterventions, 176 (39.4\%) were non-revision reinterventions and $39(8.7 \%)$ were revision ACL reconstructions performed with a bone-patellar-tendon-bone or quadriceps tendon autograft (Figure 1). Twenty-nine (6.5\%) patients reported a traumatic re-rupture event, and 10 (2.2\%) patients underwent revision ACL reconstruction due to increasing knee instability without a traumatic event. Fifty-five (12.3\%) patients underwent a major non-revision reintervention, and 121 (27.1\%) patients underwent a minor non-revision reintervention. Major non-revision reinterventions requiring arthroscopy included 26 (5.8\%) scar tissue debridements with hardware removal resulting from ROM deficits, 14 (3.1\%) partial meniscectomies, four (0.9\%) meniscal sutures, four (0.9\%) arthroscopies due to crepitation or knee pain, two (0.4\%) arthroscopic lavages due to septic arthritis, one (0.2\%) meniscal suture and partial meniscectomy, and one (0.2\%) cartilage repair procedure. Major non-revision reinterventions requiring open surgery included one anterolateral ligament reconstruction (0.2\%), one wound debridement (0.2\%), and one hematoma evacuation $(0.2 \%)$.

Minor non-revision reinterventions included 97 (21.7\%) hardware removals, 20 (4.5\%) hardware removals with MUA, and four MUAs alone (0.9\%). All minor non-revision reinterventions were performed under analgosedation and/or local anesthesia. Hardware removal was performed in $63(64.9 \%)$ patients due to local discomfort, in 28 (28.9\%) patients because of patients' desires to be without discomfort, in five (5.2\%) patients due to a ROM deficit, and in one (1.0\%) patient because of a local skin infection. MUAs were performed when knee flexion was below $130^{\circ}$.

Table 3

Reinterventions in 446 anterior cruciate ligament repairs with dynamic intraligamentary stabilization.

\begin{tabular}{lrl}
\hline Number of reinterventions & Frequency & \\
\hline 1 & 190 & $42.6 \%$ \\
2 & 21 & $4.7 \%$ \\
3 & 2 & $0.4 \%$ \\
4 & 1 & $0.2 \%$ \\
5 & 1 & $0.2 \%$ \\
Total & 215 & $48.2 \%$ \\
\hline
\end{tabular}




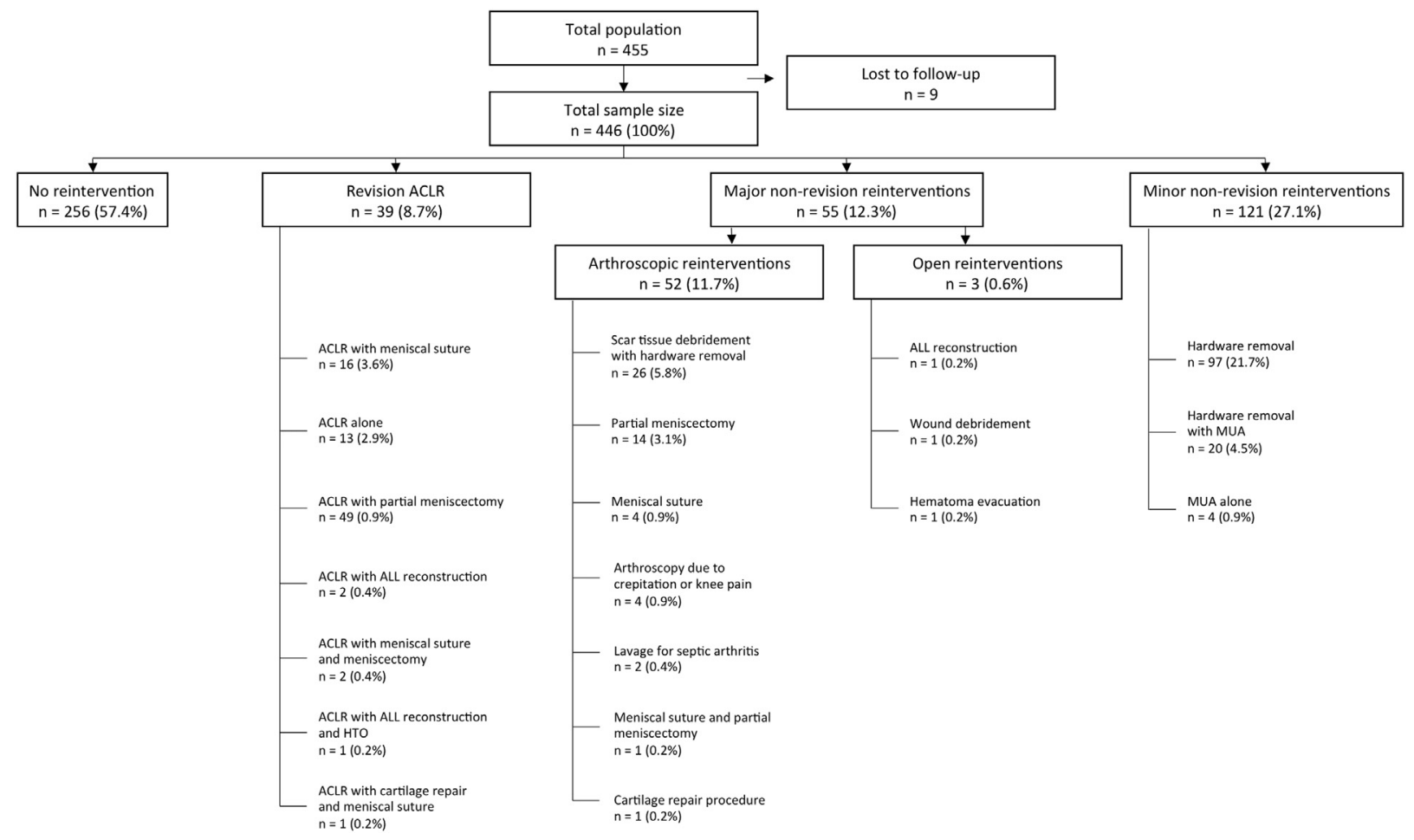

Figure 1. Reasons for revision anterior cruciate ligament (ACL) reconstructions (ACLRs), major and minor non-revision reinterventions in 446 ACL repairs with dynamic intraligamentary stabilization (DIS). ALL, anterolateral ligament; HTO, high tibial osteotomy; MUA, manipulation under anesthesia.

The mean time to the first reintervention was 13.0 months, and the mean time to the second reintervention was 19.8 months. The 29 re-ruptures occurred at a mean interval of 16.7 months, and revision ACL reconstructions were performed an average of 21.2 months after DIS treatment.

\section{Discussion}

During the follow-up of patients after primary ACL repair with DIS, we observed that several patients required a subsequent intervention. To compare the need for secondary interventions after DIS with previously published data on reinterventions after ACL reconstructions (ACLR), we determined the frequency, nature, and timing of all revision and non-revision reinterventions after DIS.

A total of 215 (48.2\%) reinterventions were performed in 190 (42.6\%) patients. 39.4\% were non-revision reinterventions and 8.7\% were revision ACL reconstructions. Major non-revision reinterventions requiring a rearthroscopy included mainly scar tissue debridements with hardware removal due to ROM deficits (5.8\%) and partial meniscectomies (3.1\%). Minor non-revision reinterventions performed under analgosedation primarily consisted of hardware removals (21.7\%) or hardware removals with manipulations under anesthesia (4.5\%).

Current studies with a comparable mean follow-up of 12-38 months report a revision rate of $1.4 \%$ up to $18.0 \%$ after ACL reconstruction with hamstring- or patellar-tendon [6-25] (Table 4, Figure 2). Revision rates increase with follow-up time, however, the highest revision rate of $18 \%$, reported by the group of Webster, was observed after only 22 months in young patients with a mean age of 17 years [25]. Nine studies with a mean 24 months of follow-up of a comparable age group (24-33 years) to our study (31 years) report revision rates between $1.4 \%$ and $9.6 \%$ [6-8,10,12,19,20,22,23]. Studies with higher follow-ups of 36 and 38 months report even higher revision rates up to $12.5 \%$. The revision rate of $8.7 \%$ that we found in our collective of ACL repair with DIS is therefore within the range of published results after ACL reconstructions. However, a direct comparison of ACL repair to reconstruction is associated with one crucial limitation: with DIS ACL repair the native ligament is preserved with no need for autograft harvesting. In case of a revision surgery, all autograft options are available and interventions are performed as one-stage procedures with no need for bone grafting.

Major non-revision reinterventions included 5.8\% arthroscopic scar tissue debridements with hardware removal and four percent arthroscopies due to new meniscal lesions. After ACL reconstruction, arthroscopic scar tissue debridement is reported to be $1.4 \%$ [13], 10.7\% [14], and 16.1\% [10] after 13, 38, and 25 months of follow-up, respectively (Table 5, Figure 3). New meniscal lesions are treated in $7.2-14.9 \%$ of patients $[9,10,12,14]$ during the first $24-38$ months after ACL reconstruction. The re-arthroscopy 
Published in final edited form as: Knee. 2018 Mar;25(2):271-278. doi: 10.1016/j.knee.2018.01.003.

Table 4

Revision rates after anterior cruciate ligament reconstructions.

\begin{tabular}{|c|c|c|c|c|c|}
\hline Study (year) [ref.no.] & Sample size $(\mathrm{n})$ & Mean age (years) & Study design & Mean follow-up (months) & Revision rate (\%) \\
\hline Andernord et al. (2015) [6] & $16^{\prime} 930$ & 25 & PC & 24 & $1.8 \%$ \\
\hline Aune et al. (2001) [7] & 61 & 26 & PC & 24 & $4.9 \%$ \\
\hline Biau et al. (2006) [18] & 1088 & NA & Meta & 36 & $3.8 \%$ \\
\hline Björnsson et al. (2015) [8] & 16,791 & 26 & $\mathrm{RC}$ & 24 & $1.4 \%$ \\
\hline \multirow[t]{2}{*}{ Borchers et al. (2009) [19] } & 322 & 28 & $\mathrm{CC}$ & 24 & $3.7 \%$ \\
\hline & & & & 24 & $8.6 \%$ \\
\hline Colombet et al. (2006) [20] & 33 & 30 & PC & 24 & $3.3 \%$ \\
\hline Dunn (2004) [9] & 3795 & 30 & $\mathrm{RC}$ & 30 & $6.2 \%$ \\
\hline Feller and Webster (2003) [21] & 26 & 26 & $\mathrm{RCT}$ & 36 & $3.8 \%$ \\
\hline Frobell et al. (2010) [10] & 62 & 26 & $\mathrm{RCT}$ & 24 & $4.8 \%$ \\
\hline Gifstad et al. (2014) [11] & 45,998 & 29 & PC & 12 & $2.6 \%$ \\
\hline Grindem et al. (2012) [13] & 69 & 27 & PC & 13 & $1.4 \%$ \\
\hline Grindem et al. (2014) [12] & 100 & 24 & PC & 24 & $1.4 \%$ \\
\hline Järvelä et al. (2008) [22] & 73 & 33 & $\mathrm{RCT}$ & 24 & $9.6 \%$ \\
\hline Kartus et al. (1999) [14] & 604 & 27 & Descriptive & 38 & $2.4 \%$ \\
\hline Lind et al. (2009) [15] & 5818 & NA & $\mathrm{RC}$ & 24 & $2.9 \%$ \\
\hline Mohtadi et al. (2016) [16] & 322 & 27 & $\mathrm{RCT}$ & 18 & $4.7 \%$ \\
\hline Suomalainen et al. (2013) [23] & 46 & 31 & PC & 24 & $8.7 \%$ \\
\hline \multirow[t]{2}{*}{ Taylor et al. (2009) [24] } & 36 & 22 & $\mathrm{RCT}$ & 36 & $9.4 \%$ \\
\hline & & 22 & & 36 & $12.5 \%$ \\
\hline Webster and Feller (2016) [25] & 354 & 17 & PC & 22 & $18.0 \%$ \\
\hline Wright et al. (2007) [17] & 235 & 23 & PC & 24 & $3.0 \%$ \\
\hline
\end{tabular}

CC, case control study; NA, not applicable; PC, prospective cohort study; RC, retrospective comparative study; RCT, randomized clinical trial.

rate for secondary meniscectomies and meniscal sutures after ACL repair with DIS is thus lower. As ACL repair must be performed within the first three weeks after injury, meniscal tears are fresh with a high healing potential and may, hence, benefit from early suture treatment [26]. In our clinic, two out of three meniscal tears detected during DIS treatment were sutured, thereby preserving their chondroprotective function [3].

Minor non-revision reinterventions consisted merely of hardware removals with and without MUA. Hardware removal after ACL reconstruction is found in 3.2\% [10] to 6.8\% [14] of patients after 25 and 38 months, respectively. MUA is reported in $1.6 \%$ of patients after 25 months of follow-up [10]. Both reinterventions were therefore much more frequent in our ACL repair cohort,

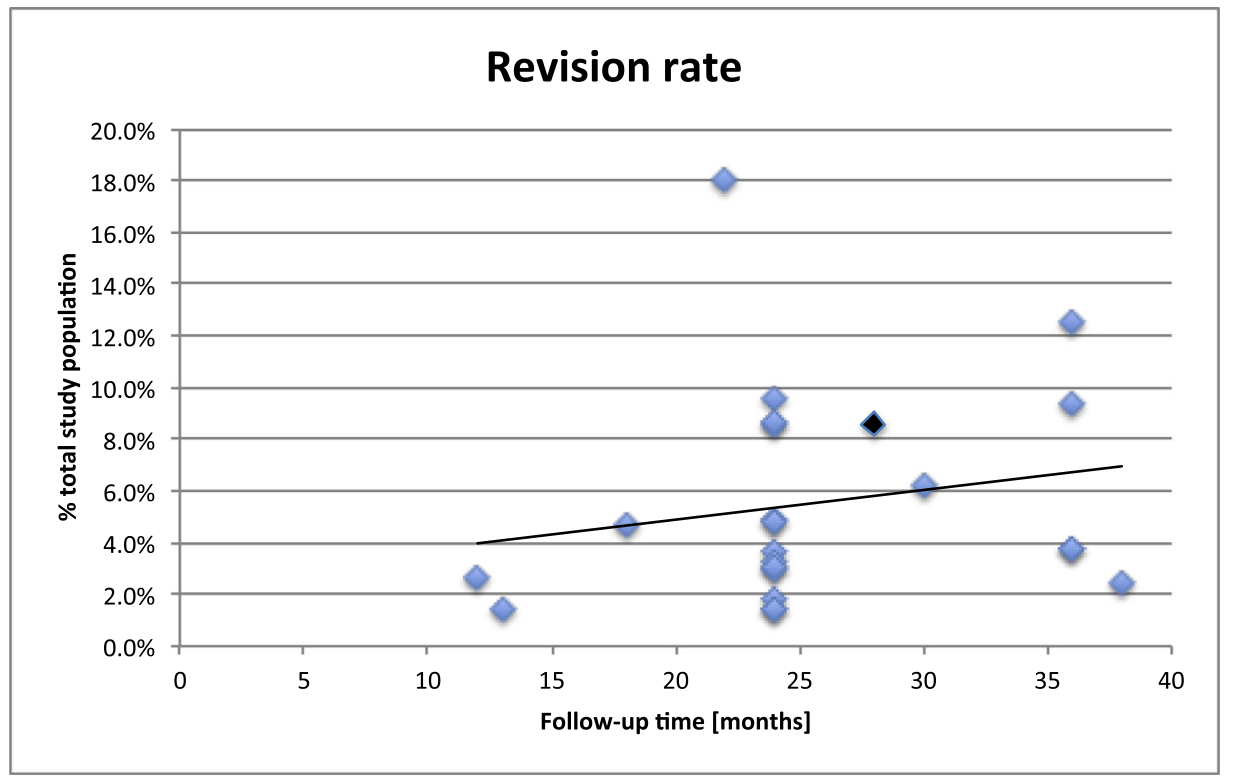

Figure 2. Scatterplot of revision rates after anterior cruciate ligament (ACL) reconstructions reported in previous literature and mean postoperative follow-up time with linear trendline. The black dot represents the revision rate after dynamic intraligamentary stabilization ACL repair. 
Published in final edited form as: Knee. 2018 Mar;25(2):271-278. doi: 10.1016/j.knee.2018.01.003.

Table 5

Secondary meniscectomies and meniscal sutures after anterior cruciate ligament reconstructions.

\begin{tabular}{llllll}
\hline Study (year) [ref. no.] & Sample size (n) & Mean age (years) & Study design & Mean follow-up (months) & $\begin{array}{l}\text { Secondary meniscectomies } \\
\text { and meniscal sutures }\end{array}$ \\
\hline Dunn (2004) [9] & 3,795 & 30 & RC & 30 & $7.2 \%$ \\
Frobell et al. (2010) [10] & 62 & 26 & RCT & 24 & $9.7 \%$ \\
Grindem et al. (2012) [13] & 69 & 27 & PC & 13 & $8.7 \%$ \\
Grindem et al. (2014) [12] & 100 & 24 & PC & 24 & $13.0 \%$ \\
Kartus et al. (1999) [14] & 604 & 27 & Descriptive & 38 & $8.6 \%$ \\
Laxdal et al. (2005) [29] & 948 & 26 & Case series & 32 & $6.9 \%$ \\
\hline
\end{tabular}

PC, prospective cohort study; RC, retrospective comparative study; RCT, randomized clinical trial.

coinciding with our own experience with ACL reconstructions, where the tibial fixation rarely has to be removed and MUA is often not necessary. Hardware removal is undoubtedly a consequence of the $10 \times 30$-mm-sized tibial implant, which can cause local discomfort. Second, the potential to perform hardware removal during a three-minute procedure under analgosedation may also have been favored; thus, the procedure was performed more frequently. The increased rate of MUA may be due to excessive scar tissue formation at the site of repair resulting in a decreased range of motion. Ateschrang et al. investigated the degree of hypertrophic scar tissue formation in the notch six months after DIS ACL repair with a diagnostic arthroscopy. They found that intraarticular scar tissue formation in the notch region was a common finding, which might be associated with microfracturing at the femoral footprint [27]. They concluded that factors influencing the degree of scar tissue formation needed further investigation with the goal of guiding a more balanced healing response [27].

The goal of future research should be to increase the $91 \%$ preservation rate after ACL repair with DIS. This goal may be achieved by a more specific selection of patients who benefit most from ACL repair, with potential exclusion of patients with unfavorable tear types, activity profiles, or particular age groups. Collagen scaffolds combined with platelet-rich plasma may guide biological functions and therefore result in less scar tissue formation [28], resulting in fewer reinterventions for scar tissue debridement and fewer MUAs. Moreover, implant downsizing would decrease the need for hardware removal due to patient discomfort and increase the tibial bone stock.

Our study has some limitations that must be considered. First, we report a variable follow-up interval ranging from 21 to 64 months. It might be possible that patients with a shorter follow-up will need reintervention at a later stage. However, more than $90 \%$ of the reinterventions were performed during the minimum follow-up period of 21 months. It is therefore unlikely that patients with a short follow-up will need further interventions in the future. Second, except for the first 10 patients, all patients were treated at one private institution caring for patients with public and private insurance. Patient expectations and the threshold for acceptance may alter the frequency of reintervention, as can the surgeon's perception of what has to be tolerated and what may be achieved by additional surgery. Third, we did not analyze any outcome measures other than reintervention. However, some patients may endure pain or a poor result without submitting themselves to a reintervention. Further, we did

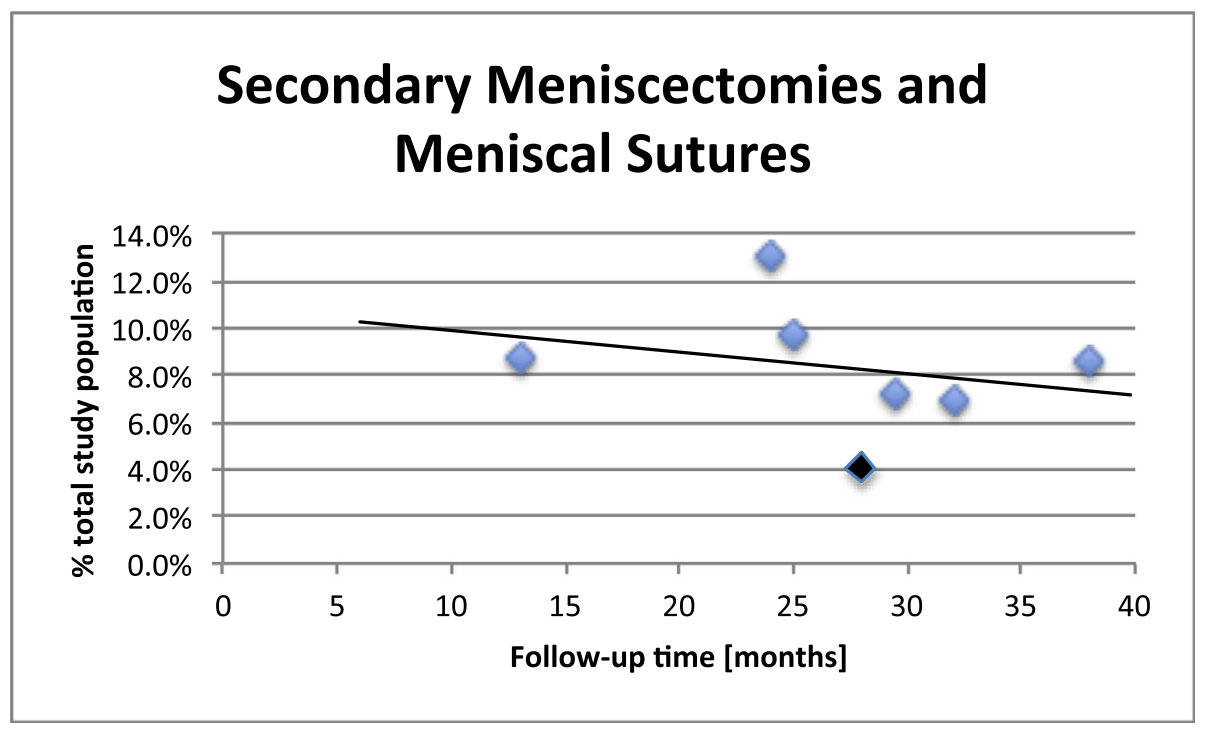

Figure 3. Scatterplot of secondary meniscectomies and meniscal sutures after anterior cruciate ligament (ACL) reconstructions reported in previous literature and mean postoperative follow-up time with linear trendline. The black dot represents the rate after dynamic intraligamentary stabilization ACL repair. 
not include potential complications that did not require a surgical reintervention (postoperative hematoma, deep vein thrombosis, or infections treated conservatively).

\section{Conclusion}

In our study, the revision rate was within the range of published results after ACL reconstructions. In 10 out of 11 patients, the native ACL was preserved with no need for autograft harvesting. If revision was required, a one-stage ACL reconstruction was performed with all autograft options available. Most of the non-revision reinterventions were minor and included hardware removals and MUAs. The re-arthroscopy rate for secondary meniscectomies and meniscal sutures was lower than that after ACL reconstruction. Early treatment of meniscal tears may be one crucial benefit of ACL repair with DIS.

\section{Conflicts of interest}

JH, SE, and PH have received reimbursements or funding from Mathys AG Bettlach, Switzerland, in the past five years. All other authors declare that they have no conflicts of interest. The authors are not compensated for this work, and there are no institutional subsidies, corporate affiliations, or funding sources supporting this work unless clearly documented and disclosed.

\section{Acknowledgments}

Edith Hofer is acknowledged for her excellent support in the acquisition of patient data and management of the database.

\section{References}

[1] Eggli S, Kohlhof H, Zumstein M, Henle P, Hartel M, Evangelopoulos DS, et al. Dynamic intraligamentary stabilization: novel technique for preserving the ruptured ACL. Knee Surg Sports Traumatol Arthrosc 2015;23:1215-21.

[2] Eggli S, Roder C, Perler G, Henle P. Five year results of the first ten ACL patients treated with dynamic intraligamentary stabilisation. BMC Musculoskelet Disord 2016;17:105

[3] Henle P, Roder C, Perler G, Heitkemper S, Eggli S. Dynamic Intraligamentary Stabilization (DIS) for treatment of acute anterior cruciate ligament ruptures: case series experience of the first three years. BMC Musculoskelet Disord 2015;16:27.

[4] Schliemann B, Herbort M, Lenschow S, Raschke MJ, Kösters C. Dynamische intraligamentäre Stabilisierung frischer Rupturen des vorderen Kreuzbandes (Ligamys). Trauma Berufskrankheit 2015;18(Supplement 3):254-9.

[5] Kohl S, Evangelopoulos D, Schär M, Bieri K, Müller T, Ahmad S. Dynamic intraligamentary stabilisation. Bone Joint J 2016;98:793-8.

[6] Andernord D, Desai N, Björnsson H, Ylander M, Karlsson J, Samuelsson K. Patient predictors of early revision surgery after anterior cruciate ligament reconstruction: a cohort study of 16,930 patients with 2-year follow-up. Am J Sports Med 2015;43:121-7.

[7] Aune AK, Holm I, Risberg MA, Jensen HK, Steen H. Four-strand hamstring tendon autograft compared with patellar tendon-bone autograft for anterior cruciate ligament reconstruction a randomized study with two-year follow-up. Am J Sports Med 2001;29:722-8.

[8] Björnsson H, Andernord D, Desai N, Norrby O, Forssblad M, Petzold M, et al. No difference in revision rates between single- and double-bundle anterior cruciate ligament reconstruction: a comparative study of 16,791 patients from the Swedish national knee ligament register. Arthroscopy 2015;31:659-64.

[9] Dunn WR. The effect of anterior cruciate ligament reconstruction on the risk of knee reinjury. Am J Sports Med 2004;32:1906-14.

[10] Frobell RB, Roos EM, Roos HP, Ranstam J, Lohmander LS. A randomized trial of treatment for acute anterior cruciate ligament tears. N Engl J Med 2010;363: $331-42$.

[11] Gifstad T, Foss OA, Engebretsen L, Lind M, Forssblad M, Albrektsen G, et al. Lower risk of revision with patellar tendon autografts compared with hamstring autografts: a registry study based on 45,998 primary ACL reconstructions in Scandinavia. Am J Sports Med 2014;42:2319-28.

[12] Grindem H, Eitzen I, Engebretsen L, Snyder-Mackler L, Risberg MA. Nonsurgical or surgical treatment of ACL injuries: knee function, sports participation, and knee reinjury. J Bone Joint Surg 2014;96:1233-41.

[13] Grindem H, Eitzen I, Moksnes H, Snyder-Mackler L, Risberg MA. A pair-matched comparison of return to pivoting sports at 1 year in anterior cruciate ligamentinjured patients after a nonoperative versus an operative treatment course. Am J Sports Med 2012;40:2509-16.

[14] Kartus J, Magnusson L, Stener S, Brandsson S, Eriksson BI, Karlsson J. Complications following arthroscopic anterior cruciate ligament reconstruction. A 2-5-year follow-up of 604 patients with special emphasis on anterior knee pain. Knee Surg Sports Traumatol Arthrosc 1999;7:2-8.

[15] Lind M, Menhert F, Pedersen AB. The first results from the Danish ACL reconstruction registry: epidemiologic and 2 year follow-up results from 5,818 knee ligament reconstructions. Knee Surg Sports Traumatol Arthrosc 2009;17:117-24.

[16] Mohtadi N, Barber R, Chan D, Paolucci EO. Complications and adverse events of a randomized clinical trial comparing 3 graft types for ACL reconstruction. Clin J Sport Med 2016;26:182-9.

[17] Wright RW, Dunn WR, Amendola A, Andrish JT, Bergfeld J, Kaeding CC, et al. Risk of tearing the intact anterior cruciate ligament in the contralateral knee and rupturing the anterior cruciate ligament graft during the first 2 years after anterior cruciate ligament reconstruction: a prospective MOON cohort study. Am J Sports Med 2007;35:1131-4.

[18] Biau DJ, Tournoux C, Katsahian S, Schranz PJ, Nizard RS. Bone-patellar tendon-bone autografts versus hamstring autografts for reconstruction of anterior cruciate ligament: meta-analysis. BMJ 2006;332:995-1001.

[19] Borchers JR, Pedroza A, Kaeding C. Activity level and graft type as risk factors for anterior cruciate ligament graft failure: a case-control study. Am J Sports Med 2009;37:2362-7.

[20] Colombet P, Robinson J, Jambou S, Allard M, Bousquet V, de Lavigne C. Two-bundle, four-tunnel anterior cruciate ligament reconstruction. Knee Surg Sports Traumatol Arthrosc 2006;14:629-36.

[21] Feller JA, Webster KE. A randomized comparison of patellar tendon and hamstring tendon anterior cruciate ligament reconstruction. Am J Sports Med 2003;31: 564-73.

[22] Järvelä T, Moisala A-S, Sihvonen R, Järvelä S, Kannus P, Järvinen M. Double-bundle anterior cruciate ligament reconstruction using hamstring autografts and bioabsorbable interference screw fixation prospective, randomized, clinical study with 2-year results. Am J Sports Med 2008;36:290-7.

[23] Suomalainen P, Moisala AS, Paakkala A, Kannus P, Järvelä T. Comparison of tunnel placements and clinical results of single-bundle anterior cruciate ligament reconstruction before and after starting the use of double-bundle technique. Knee Surg Sports Traumatol Arthrosc 2013;21:646-53.

[24] Taylor DC, DeBerardino TM, Nelson BJ, Duffey M, Tenuta J, Stoneman PD, et al. Patellar tendon versus hamstring tendon autografts for anterior cruciate ligament reconstruction: a randomized controlled trial using similar femoral and tibial fixation methods. Am J Sports Med 2009;37:1946-57.

[25] Webster KE, Feller JA. Exploring the high reinjury rate in younger patients undergoing anterior cruciate ligament reconstruction. Am J Sports Med 2016;44: $2827-32$ 
Published in final edited form as: Knee. 2018 Mar;25(2):271-278. doi: 10.1016/j.knee.2018.01.003.

[26] Verdonk R, Madry H, Shabshin N, Dirisamer F, Peretti GM, Pujol N, et al. The role of meniscal tissue in joint protection in early osteoarthritis. Knee Surg Sports Traumatol Arthrosc 2016;24:1763-74.

[27] Ateschrang A, Ahmad SS, Stockle U, Schroeter S, Schenk W, Ahrend MD. Recovery of ACL function after dynamic intraligamentary stabilization is resultant to restoration of ACL integrity and scar tissue formation. Knee Surg Sports Traumatol Arthrosc 2017 [Epub ahead of print].

[28] Murray MM, Fleming BC. Biology of anterior cruciate ligament injury and repair: Kappa Delta Ann Doner Vaughn Award paper 2013. J Orthop Res 2013;31: $1501-6$.

[29] Laxdal G, Kartus J, Ejerhed L, Sernert N, Magnusson L, Faxén E, Karlsson J. Outcome and risk factors after anterior cruciate ligament reconstruction: a follow-up study of 948 patients. Arthroscopy J Arthrosc Relat Surg 2005;21(8):958-64. 